\title{
“LE SALVÉ LA VIDA": EL PECHO VIVIDO, LA LECHE NARRADA. HISTORIA(S) DE AMA DE TETA, SUR DE ESPAÑA, SIGLO XX
}

\author{
Ester Massó Guijarro ${ }^{1}$ \\ ${ }^{1}$ Universidad de Granada, Departamento de Antropología Social y Cultural, \\ Granada, España
}

\section{Obertura: crónicas lácteas}

"El pecho ha sido, y seguirá siendo, un indicador de los valores de la sociedad." (Yalom 1997:325)

"[...] ha vuelto la cara del almidonado pecho de la nodriza, ese pequeño monte volcánico estremecido de leche y venas azules [...]."

(García Lorca en Cardwell 2003:23)

Este trabajo es la historia del pecho de una mujer, o mejor dicho de su leche. ¿O debiéramos decir de su agencia en relación al producto fisiológico que es su fluido lácteo, y qué decisiones tomó sobre ello, cómo intervino en la realidad para transformarla a través de su agencia láctea?

Volvamos a empezar. Este trabajo es la historia de unas tetas, de las de una mujer; de dos mujeres, en realidad, madre e hija; una viva, la hija, que narra la memoria desde la vida, y otra muerta, la madre, que es narrada como origen de linaje; una auténtica estirpe de amas de teta nunca enunciadas por la academia, silenciadas en su lugar de "tierra de nadie epistémica", como nodrizas que han sido no de los más ricos (veremos que abundan los estudios sobre las nodrizas regias, las más privilegiadas), tampoco las más depauperadas (igualmente han proliferado los estudios sobre esclavas ab-usadas como nodrizas); así pues, amas de teta más bien en una posición de clara subalternidad pero cuya voz, por una u otra razón, aún está pendiente de escucha - al menos en el contexto que aquí se describirá. 
Este trabajo cuenta historias que dieron vida a la que hoy es plaza de la catedral de la ciudad de Granada, al sur de España, la Plaza de las Pasiegas, y cuyo inmenso silencio hace que ni una mísera placa informativa exista hoy en este emblemático lugar. Las "pasiegas" fueron amas de teta emigradas de la Vega del Pas, en Cantabria, en el lejano norte de España, y cuya costumbre de exponerse en dicha plaza fue emulada por las propias granadinas. Nuestras dos mujeres, nuestras dos voces lo cuentan: todavía es una historia viva.

Aquí vamos a hablar, pues, de nodrizas, de mujeres humanas que amamantan, generalmente a cambio de bienes monetarios y materiales, a criaturas que no han parido, que no son biológica ni simbólica ni putativamente suyas. ¿Por qué sucede esto? La allomaternal nursing (Hewlett y Winn 2014), el hecho de que una hembra de una especie mamífera amamante a una criatura ajena biológicamente, ha sido perenemente registrado, existe en la naturaleza por motivos diversos - no monetarios evidentemente; también lo hace, empero, en la culturaleza ${ }^{1}$ humana. En el caso humano, hay de facto multitud de formas de allomaternal nursing que no involucran el dinero. Aquí, sin embargo, vamos a hablar, como hemos comenzado diciendo, de nodrizas, de mujeres que han hecho empresariado de sus propios pechos, de su propia leche. Busco rescatar, dignificándola a través de su visibilización, una memoria oral todavía presente y viva en la figura de las ancianas que recuerdan esa época - entre los años treinta y ochenta del pasado siglo en las áreas depauperadas y los barrios marginales del sur de España, como veremos - y que ofrecieron su leche para sobrevivir ellas mismas y sus familias.

Compartir leche, o alimentar a criaturas no biológicamente propias/ paridas con el propio cuerpo, no es nada nuevo entre los humanos: las madres lo han hecho siempre, por motivos muy diversos, con o sin contraprestación económica o de otros dones diversos. Se ha realizado por motivos altruistas y también puramente económicos. Como precisan Ozturk Can et al (2014:559), dicha lactancia puede realizarla una amiga, una parienta o una mujer empleada por la familia. Se ha realizado en condiciones de sumo respeto, incluso reconocimiento y prestigio socio-morales (como en el caso de las nodrizas regias), y también en condiciones de franca subalternidad, desde la mera pobreza hasta la abierta esclavitud.

Suele decirse a menudo que "la teta es lo natural"2". Es lo natural... y lo cultural. La historiografía de la lactancia humana muestra qué tan absolutamente distinto puede ser el significado cultural y la suma de atribuciones simbólico-prácticas en torno a la lactancia y la leche humana, en cada contexto y época donde nos hallemos. Actualmente qué se hace con la leche y, sobre todo, quién decide sobre ello y con qué constricciones, deviene un objeto de estudio fundamental, de dilema político y económico, de intenso debate social. 
Este trabajo se centra en algo mucho más humilde y concreto: una historia de nodriza(s) a la vieja usanza, fuera de los cánones, rigores y diásporas multinacionales y neoliberales contemporáneas. Eso es lo que hace esta historia sencilla y a la vez imprescindible: pocas mujeres pueden ya contarla, pocas están vivas.

\title{
[Métodos] Narrando la vida láctea: amamanto luego existo
}

\begin{abstract}
“En El ocaso de los Dioses, Nietzsche formula tres tareas por las que se requieren educadores: hay que aprender a mirar, a pensar y a hablar y escribir [...] Aprender a mirar significa «acostumbrar el ojo a mirar con calma y con paciencia, a dejar que las cosas se acerquen al ojo», es decir, educar el ojo para una profunda y contemplativa atención, para una mirada larga y pausada."
\end{abstract}

(Han 2010:53).

A la respuesta fundamental "quién soy yo", clave del racionalismo filosófico occidental, la filósofa italiana Adriana Cavarero (2007) precisa que se responde narrando la propia vida, contando la vida. Existimos en cuanto que podemos narrarnos, de forma irrepetible. Si nos narramos es a causa, también, de nuestra condición sensorial, lo que pretende explorar la contemporánea antropología de los sentidos: nuestra disciplina se torna indefectiblemente reflexiva, generizada, corporizada y, por ende, visual (Pink 2010).

Debo reclamar, sin embargo, que no creo que la antropología esté realmente diciendo nada nuevo: recordemos solo a Nietzsche cuando afirmaba ${ }^{3}$ que toda verdad no podía venir sino por los sentidos, que los sentidos (lejos del racionalismo) no podían sino ser la fuente certera para las condiciones de verdad. Así, de un modo otro, toda época parece confluir en la verdad inapelable de que, para tantos sujetos humanos, personas o, sencillamente, (autodenominadas) mujeres, su condición de breasted, ${ }^{4}$ de tener pechos como metáfora de todas sus implicaciones, y para el caso que nos ocupa, la condición lactante de los mismos, ha condicionado, determinado incluso, su existencia de un modo que el pensamiento apenas ha sabido ver, en el mejor de los casos, cuando no ha ignorado completamente, en el caso más frecuente.

Bourdieu (1998) pensará sobre la metodología de las historias de vida, a través de este sentido profundo de narración que plantea Cavarero, pero impostando una cierta mirada crítica, encontrando un carácter de dispositivo en la historia de vida, en tanto que el sujeto que la narra rearticula su vida, le busca una teleología: “... construye el sentido de su vida y lo articula azarosamente para el otro, seleccionando y ordenando acontecimientos al 
servicio del entrevistador" (Vera Lugo y Jaramillo Marín 2007:251), incluso que tal vez pueda cuestionar la autenticidad de la narración. Pero, al final, ¿quién determina que comprendemos a cabalidad el discurso del otro, de la otra, más allá de lo que ella o él sea capaz de expresar y más acá de lo que nosotras, nosotros, seamos capaces de entender? No nos queda sino la palabra, la afirmación, la confianza, la fe, al fin, en la palabra como luz de la sangre.

Desde esa mirada larga y pausada, esa contemplativa atención que Nietzsche reclama, lo que se presenta aquí es una historia, dos historias de vida engranadas ya que son las de una madre y una hija, ambas nodrizas o amas de teta, en su propia terminología. Preferimos llamarlas, sin embargo, historias de vida lactante o incluso herstories en la estela del feminismo negro y poscolonial (Massó Guijarro 2015:11).

No es baladí reivindicar la dignidad, la necesidad de ser oídas, reconocidas y narradas, de las herstories de amamantamiento; antes bien, reclamar estas narraciones lácteas que aquí se presenta desafía, entre muchas otras cosas, una larga tradición de lucha feminista colonizada por el propio patriarcado, donde la rebelión misma se funda en su semilla (¿̇acaso por pura necesidad militante?). Decía Beauvoir (en Puleo 2009:127): “La gestación y los trabajos domésticos [...] son repetitivos, encierran a las mujeres en la inmanencia, no producen nada nuevo. Engendrar y amamantar no son 'actividades', son funciones naturales, no suponen ningún proyecto". ${ }^{5}$

Pues bien: aquí se reclama ese amamantar como una actividad, como un proyecto de vida; más aún, una ontología, en su más puro sentido filosófico y metafísico de estudiar lo que hay, así como las relaciones entre los entes, o la relación entre un acto y sus participantes. Lo que presentamos aquí es, pues, una historia (historia de vida lactante): la de las nodrizas granadinas que, como tantas mujeres, ejercieron el oficio de ama de teta, entre otras prácticas, desde situaciones de subalternidad e incluso exclusión social, mujeres que tuvieron que mendigar o habitar en cuevas reconstruidas o viviendas sociales en algunos de los barrios más pobres de Granada; mujeres que, sin embargo, señalan como fundamental (haciendo revolverse en su tumba a Beauvoir) lo que hacían, lo mucho que significaba (le salvé la vida) dar sus pechos, la leche de sus pechos. Lo que contamos aquí es una historia de vida o, en su versión más concreta, relato de vida, pero no cualquier historia de vida, no de cualquier vida ni cualquier historia, sino que empleamos instrumental y estratégicamente esta técnica clásica orientada de modo específico a la lactancia, en lo que se ha llamado "historia - herstory - de vida láctea", en un diverso juego de palabras. El propio "camino de la leche" como metáfora vital. ${ }^{6}$ 


\title{
[Marco teórico] Sobre la lactancia asalariada: el oficio de ama de teta, o dar leche a quien no se ha parido
}

\begin{abstract}
"Hablo de atribuir un valor monetario a un trabajo no remunerado, productivo y reproductivo. Este proceso, llamado imputación, haría visible este tipo de trabajo, influiría en la política y en los conceptos, y cuestionaría los valores." (Waring 1994:27)
\end{abstract}

\section{Dos grandes modos (¿diferenciados?) de lactar: dar o vender}

En 2015 La Leche League International publica un documento ${ }^{7}$ sobre la política de donación de leche y las diferentes modalidades de amamantamiento a criaturas a quien no se ha parido, por así decir, asumiendo la siguiente dicotomía. ${ }^{8}$

- "Wet nursing", que podemos traducir como amamantamiento asalariado o "empleado", incluso: el amamantamiento completo de un bebé ajeno, a menudo por un pago ("the complete nursing of another's infant, often for pay"). El Diccionario de la Real Academia Española ${ }^{9}$ redirige, directamente, la entrada "nodriza" a la de "ama", y en ella (entre otras no oportunas aquí): "mujer que cría a sus pechos una criatura ajena" (en "ama de leche" y "ama de cría", indistintamente: "mujer que cría a una criatura ajena"). El Oxford Dictionary indica literalmente, en la entrada para "wet nurse":10 "In the past, a woman employed to give her breast milk to another woman's baby"; así, explicita los términos "empleada" y "en el pasado", dejando patente la obsolescencia del término en su praxis contemporánea. (Muchos elementos a los que apunta este trabajo desafiarán en cierto modo esta definición.)

- "Cross nursing", que podemos traducir como lactancia cruzada o compartida: ${ }^{11}$ la lactancia ocasional de un bebé ajeno mientras la madre continúa amamantando a su propia criatura, a menudo en una situación de cuidado de aquél ("the occasional nursing of another's infant while the mother continues to nurse her own child, often in a child care situation"). Otra denominación posible podría ser la de "allomaternal nursing", mencionada en la introducción.

Efectivamente, la historiografía de la lactancia distingue entre su práctica solidaria o altruista y su práctica mercantil, asalariada o mercenaria, pero a menudo se reconoce también lo difuso de sus límites, ya que con frecuencia 
coexistían o se alternaban ambos tipos de uso. En todo caso, raramente no se desarrollaban vínculos afectivos entre las partes implicadas, de modo que la lactancia difícilmente ha sido una simple práctica asalariada más; de ello dan buena cuenta las expresiones, tan extendidas interculturalmente, como "madre de leche" o "hermano de leche" (de hecho, en numerosas culturas se asume que la leche genera parentesco de forma directa, de modo que el matrimonio con un "hermano de leche" es prohibido como tabú de incesto, por ejemplo; cf. Soler 2011).

Resulta de especial relevancia en las discusiones antropológicas contemporáneas sobre parentesco, relacionalidades, fluidos y sustancias, el trabajo de la antropóloga Janet Carsten (1997). En su magnífica obra The Heat of the Hearth. The Process of Kinship in a Malay Fishing Community, la autora británica discute sobre comensalidad, leche y agencia relacional, concluyendo que el parentesco es un proceso, no un estado; así, las personas pueden devenir parientes a lo largo de su vida a través de las acciones cotidianas de las mujeres entre sus diferentes hogares; la identidad cultural, en fin, también en lo respectivo al parentesco es fluida y mutable. El parentesco de leche clásico en tantas culturas entroncaría así con la tesis de Carsten sobre la generación fluida del parentesco.

La lactancia solidaria o altruista, como práctica frecuente en grupos y sociedades con escasa diferenciación social y frecuente en zonas rurales (aún hoy, especialmente en grupos de recolectores-cazadores - Hewlett y Winn 2014), ha sido ampliamente estudiada. ${ }^{12}$ Si bien en este tipo se entiende que no existe una contraprestación monetaria - o material - automática, cualquier forma de intercambio supone contraprestaciones y consecuencias ("Biological fluids are exchanged and some costs are involved for the provider" - Hewlett y Winn 2014:226). Ozturk Can et al. (2014) presentan un estudio epidemiológico sobre las prácticas de compartir leche en comunidades turcas contemporáneas para analizar las visiones sobre este hecho. Concluyen, principalmente, que el uso de una nodriza constituye una práctica en desuso, frente al uso de leche de otras madres (donantes en bancos de leche, por ejemplo).

Por otro lado, el amamantamiento a huérfanos, expósitos, "parias" o "despreciados" (Rodríguez García 2017) en general, a lo largo de la historia, ha ido vinculado a las diversas prácticas de acogimiento de la orfandad, y normalmente las nodrizas de los niños expósitos provenían de los estratos más humildes de la población. ${ }^{13}$ En las nodrizas de las inclusas (instituciones clave dentro del proceso de regularización y burocratización en el marco político de la gestación de los estados nacionales), así como en las redes vecinales, es donde más se contempla la realidad del parentesco de leche 
(Martínez Sabater 2014:35ss, 42ss), por estar ligado sin duda al altruismo recíproco y la cooperación social.

Otro gran campo de estudio es la práctica de las amas de cría negras, ligada a la esclavitud, tanto en ultramar como en las metrópolis europeas. Destaca, por ejemplo, el estudio de West y Knight (2017) sobre las nodrizas relacionadas con la esclavitud (no asalariada por razones obvias) en las Antillas del Sur.

\section{El oficio de ama de teta: ambivalencia y poder}

Presentamos ahora la literatura revisada y el estado de la cuestión sobre las nodrizas asalariadas (el "wet-nursing"), el ser ama de teta como oficio, cuestión que nos ocupa aquí, y ya que este trabajo se centra pues en ese tipo de lactancia donde una o varias mujeres que no son la madre biológica amamantan a otra criatura a modo de trabajo y/o siempre - o al menos de modo previamente pactado - mediando una contraprestación, económica o en especie.

Un elemento crucial que refleja, a mi juicio, la historiografía sobre la lactancia humana es el de la tremenda ambigüedad: la ambigüedad o ambivalencia en la consideración misma de la leche humana, así como de su don o práctica; es decir, hallamos por un lado ejemplos de gran consideración de la misma (en la línea del valor simbólico atribuido a la leche de diosas en la mitología ${ }^{14}$, por ejemplo, o como veremos ahora en la importancia de las nodrizas regias) y, por otro lado, y a tiempo real, ejemplos de gran descrédito y desprestigio simbólico para con la misma (en la línea de las críticas feministas de Waring mencionadas en la introducción, por ejemplo, o de la misma Simone de Beauvoir recién citadas).

Muchos estudios hasta la fecha se han centrado en analizar las experiencias del oficio de nodriza en clases altas. En el panorama español destaca de forma significativa el trabajo de Soler $(2011)^{15}$ sobre las nodrizas pasiegas, algo así como las vip de las amas de teta, por motivos diversos, que llegaron a encumbrarse hasta el punto de ser, proverbialmente, las amas de teta de las casas reales. Esta investigación etnográfica analizó la historia social de las nodrizas domésticas del norte de España entre 1830 y 1940, estructurada en la migración de las mujeres campesinas-ganaderas para emplearse como amas de cría en familias acomodadas, desde la burguesía hasta, incluso, la casa real.

Cabe destacar que, incluso para estas amas vip, señala Soler que siempre persistía la impresión - a ello obedecía precisamente el empleo de una nodriza - de que lactar no era algo propio de damas, enfrentando este rol - el de dama de alcurnia - al de campesina (Soler 2011:137ss); así, lactar 
por dinero, incluso en las mejores condiciones posibles, no deja de significar un símbolo de sumisión y pobreza, como algo más cercano a la naturaleza, primaria e instintiva (Soler, 2011). ${ }^{16}$

Por otro lado, resulta igualmente significativo el olvido que sucedía con respecto al hijo propio, biológico, de la nodriza, que si era considerado en algún caso, lo era solo para chequearse su salud y que sirviera de testigo de la buena leche de la madre (Thorley 2015). A menudo la nodriza, además de duramente escrutada, resultaba directamente culpada si existían problemas de salud en algún momento, cuando el estudio de Thorley (2015) muestra que eran ellas mismas las que llegan a contraer enfermedades a raíz de este empleo - por ejemplo sífilis de un bebé que la padeciera de forma congénita; la nodriza acababa contagiando a su propia familia, y además siendo culpada como origen de la enfermedad.

Sarasúa (1994) presenta un análisis histórico sobre el oficio de nodriza como parte del servicio doméstico y su propia especificidad (entre otro tipo de funciones y relaciones "criados-amos"), en el Madrid de los siglos XVIII y XIX. Con la generalización a fines del XIX y sobre todo del XX de una clase burguesa/media importante, se generaliza también la práctica de la nodriza en este tipo de familias, si no nobles y muy ricas, al menos de cierto estatus.

Siles González (1996) y Martínez Sabater (2014) presentan formidables estudios de las nodrizas en ámbitos urbanos e industriales, que trabajaban para las crecientes clases burguesas, especialmente en la ciudad de Alicante (levante español). Como bien precisa Siles González, este grupo social va a representar más que ningún otro un ejemplo de síntesis fisiológica, social y laboral que acontece en el siglo XIX y primer tercio del XX. Estos estudios señalan cómo las nodrizas, en tanto que grupo laboral diferenciado, pudieron ejercer cierto poder en sus condiciones de trabajo dada la alta demanda que existía del mismo. Eran algo así como las "privilegiadas" del servicio doméstico (Martínez Sabater 2014).

Hoy en día los bancos de leche, a través de canales altruistas por un lado, y el comercio internacional de leche humana, ${ }_{1}^{17}$ por otro, reflejan como se ha "globalizado" o, dicho de otro modo, insertado en la comprensión del mundo neoliberal, los viejos usos dilemáticos de la leche humana, los pechos humanos y, en definitiva, lo que las madres recientes hacen, pueden, quieren o no, en función de sus contextos, en torno a criaturas lactantes que no son biológicamente propias.

\section{Nodrizas desfavorecidas: historias vivas sobre empoderamiento lácteo}

Como impresión general, tengo para mí que todos los usos de lactancia mercenaria recogidos en la historiografía, salvo en las que se daban en 
las clases muy altas (nobles e incluso regias), preponderan las prácticas abusivas - sexuales, salariales, familiares y afectivas incluso en tanto que a menudo se forzaba la separación de la madre con su propia criatura o bien esta había muerto - y las relaciones de poder, en las que la subalternidad de las nodrizas brillaba en una pura intersección de precariedad social. Ello no significa necesariamente que las nodrizas fueran sujetos impolíticos ${ }^{18}$ o que todas padecieran una situación peor que la de cualquier otra clase social.

Sí que podemos destacar, como conclusión general de todas nuestras revisiones, que existe un control fundamental ejercido sobre la persona de la nodriza, de su cuerpo, de sus conductas sexuales (en general, prohibido el contacto sexual con personas adultas, sobre todo cuando eran empleadas por clases altas), incluso de sus dimensiones corporales, su moral religiosa y hasta de la forma de sus pechos o pezones (Soler 2011; Hernáiz Gómez y Sáiz Puente 2010). Naturalmente, la relación proporcional es directa entre la clase social empleadora de la nodriza y el grado de control y exigencias sobre ella: si era al bebé de un rey a quien iba a amantar, el nivel de escrutinio sobre el ama devenía máximo, activándose todos los prejuicios epocales sobre las diversas formas de contaminación de la leche y, por tanto, también de preservar su pureza. Ello pasaba por preservar la pureza del cuerpo nutricio, en todas sus dimensiones. Y cierto es que, a menor clase social de las criaturas - por ejemplo, niñas abandonadas en una inclusa - menos exigencias al ama.

Resulta interesante pensar que la realidad de las amas de cría tiene sentido precisamente en proporción directa a la desafección (por el motivo que sea) de las madres - y la sociedad en general - a dar el pecho a sus propios hijos. No hay mejor muestra de que la lactancia, pese a los discursos de las diosas amamantando, etc., en realidad no ha sido una realidad considerada deseable en muchos momentos. Y, a pesar también de aquellas significaciones "buenas", hay siempre algo que controlar o constreñir en la leche materna, la leche de pecho de mujer, como lo muestra el tema de la "leche de la bruja" (Potts y Short 2001:168).

Por otro lado, Waring (1994) realiza una crítica fundamental desde la economía feminista a cómo la lactancia materna ha sido objeto de un prestigio nulo en la historia económica, al no haber sido considerada como alimento por los planificadores. Waring (1994) señala cómo la leche materna ha desempeñado un papel histórico en el racismo y el clasismo, ya que las amas de cría y niñeras eran en el sur de Estados Unidos negras y en el Reino Unido, mujeres "trabajadoras" o de clase baja.

Tras la reciente revisión, y a pesar de la ingente y notable bibliografía publicada hasta la fecha, este trabajo pretende cubrir un hueco informativo importante sobre dicha lactancia mercenaria en cierto lugar y en ciertos 
contextos sociales. Hablamos del caso de la ciudad de Granada y, especialmente, del siglo XX, entre los años 1930 y 1980 aproximadamente - cuando, además, la leche de fórmula ya estaba relativamente generalizada. Además de la documentación histórica y de archivo, inicié un proceso de búsqueda de mujeres aún vivas que hubieran trabajado como nodrizas, ama de tetas en su nombre popular en esta región española. La mayor parte de estas posibles interlocutoras, sin embargo, han fallecido, al encontrarnos, ya en 2017, cada vez más lejos de un tiempo en el que el biberón y la fórmula ya había empezado prontamente a limitar la lactancia materna.

Con todo, tuvimos la inmensa fortuna de poder contactar y conocer a una mujer, ya pasados sus setenta, que trabajó como nodriza, hija además de otra ama de teta. El caso resulta de gran interés porque ha permitido analizar cuestiones de enjundia, tanto en cuanto a las prácticas y creencias específicas de la lactancia en sí misma (lo que era buena leche y no, cómo se analizaba, etc., asuntos que se han ido confrontando en la bibliografía), como diversos hechos sociales vinculados con este tipo de nodrizas subalternas, su relación con la institución La Gota de Leche en Granada ${ }^{19}$ y, muy especialmente, valores que hemos encontrado en su forma de amamantar, tanto a los niños a quienes amamantaron por dinero, como a sus propios hijos y, sobre todo, a quienes amamantaron por puro altruismo y relaciones de ayuda mutua (sin ser hijos de sus empleadores, ni tampoco hijos propios) en entornos sociales sumamente desfavorecidos en lo social.

Sobre todo, y en la línea señalada en el apartado metodológico, lo que se presenta aquí es una memoria oral, una historia viva: de cómo estas mujeres resultan inclasificables en las categorías habituales de estudios sobre nodrizas porque no han sido pasiegas ni tampoco de / para clases privilegiadas, pero tampoco han sido esclavas ni negras ni mestizas ni moriscas y, sin embargo, han existido en situaciones a menudo de exclusión social, viviendo de y gracias a sus pechos, a su leche, dando vida a otras personas de formas directas e indirectas; a menudo por dinero pero también, como veremos, por pura bondad. En todo ello brilla poderosamente la impresión de que, como veremos, pechos y leche, leche y pechos, constituían una fuente de empoderamiento real.

\section{Estudio de caso ${ }^{20}$}

“[...] aunque por conjeturas verosímiles se deja entender que se llamaba Quejana. Pero esto importa poco a nuestro cuento; basta que en la narración dél no se salga un punto de la verdad" (Cervantes Saavedra 1994:100). 


\section{Presentación}

En la primavera de 2016 establecí contacto con una antigua ama de teta (como se llaman a sí mismas), residente en un pueblo del cinturón de Granada $^{21}$ (Andalucía, al sur de España) desde hace casi dos décadas, e hija a su vez de otra ama de teta, ya fallecida, que acudía a la Plaza de las Pasiegas para ofrecerse como tal. Se ha reconstruido, a través de la entrevista en profundidad (y según la herstory de vida láctea recreada en el epígrafe de métodos) ambas historias de vida lactante. Los alias respectivos que usaré serán: Olema (nodriza 1, madre de nuestra interlocutora, ya fallecida) y Ani (nodriza 2, nuestra interlocutora directa).

Olema, nacida en torno a los años veinte del pasado siglo, oriunda de Granada y pobre, casó en la adolescencia con un hombre de extracción social muy superior, oriundo de Zamora (región mucho más al norte), que viniendo de viaje se enamoró de la joven mientras ella trabajaba limpiando ("de freganchina") en las oficinas de la Alhambra. A ese trabajo le acompañaría, años más tarde, su hija Ani (nacida a inicios de los años 40 del siglo $\mathrm{XX}^{22}$ ), que le ayudaría a limpiar "desde chica", mientras bailaba y cantaba para los turistas extranjeros, que le daban pequeñas limosnas por sus párvulas actuaciones improvisadas.

La hipergamia del marido le supuso el castigo de ser desheredado por parte de su familia de origen, lo que condujo a la familia de Olema (llegó a parir veinte hijos, de los que siete alcanzaron la adultez) a una existencia de franca pobreza, en situación de exclusión social a menudo, pasando de unas a otras viviendas sociales. Todo ello, además de la profesión de nodriza, se reproducirá en la vida de su hija Ani.

Olema, en esta coyuntura, y especialmente al enfermar su marido del corazón y no poder éste sostener a su familia con empleo remunerado, se convierte en la proveedora de la misma comenzando a trabajar de ama de teta, a raíz de acudir a la Plaza de Pasiegas a ofrecer sus servicios y lograr allí, proverbialmente, un buen empleo de nodriza en casa de unos "señoritos ricos" de Calle Recogidas (centro comercial e histórico de la ciudad). Ani, como su madre, y ante los largos períodos de desempleo de su propio marido, sostuvo a la familia ejerciendo de ama de teta, entre otras ocupaciones como coger aceituna o la propia mendicidad ("Yo he trabajao muncho, he pedío limosna... me cogía mi cestico y me iba a pedir... por ahí a San Juan de Dios, iba pidiendo"23). Narra su propia vida como experiencia realmente dura: cómo se construían cuevas con restos de muebles o comían en comedores solidarios, etc., pasando de unas a otras viviendas sociales. Con respecto a ello, según la narración de Ani, era ella en muchas ocasiones la principal proveedora de la familia, aunque fuera a través de la 
mendicidad directa o de la caridad, por ejemplo, a través de ropa o comida que ella iba a recoger a casa de señoritas ricas:

He pedío yo hasta limosna. Me iba a pedir con mis niñillos, chicos, porque mi marío no trabajaba... se iba a vender, no ganaba, y me iba con mis señoricas to las que conocía... y venía cargá de ropa de comida y de tó, a mi casa, cuando yo vivía ya en el Polígano, y en la Virgencita ${ }^{24}$ igual. Yo he pasao muncho. Yo he pasao muncho muncho muncho muncho, ipero muncho! Cargá de hijos... con mala vida... y mu de tó. Pero muncho he pasao.

$\mathrm{Su}$ historia de lactancia apunta a tres elementos vivenciales o experiencias cruciales y distintas entre sí, aunque obviamente relacionadas, que desagregaremos a continuación.

\section{La teta para quién}

\section{- a) La teta para quien paga: el oficio de ama de teta en Granada}

Aquí exploraremos sobre el oficio de ama de teta, la práctica del amamantamiento como empleo remunerado comprendidos en las historias. Esta es en realidad la parte fundamental del presente estudio, y donde además hemos logrado rescatar, a través de la narración de Ani, no solo su experiencia sino también la de su madre, al menos lo rescatable a través de sus recuerdos (el único modo, al fin, de exploración de memorias orales). Así, a través de ellos hemos sabido cómo narraba Olema que funcionaba la exposición pública en la plaza de la catedral de Granada de las amas de cría $^{25}$, que se presentaban en este espacio público vestidas con delantales blancos, tratando de mostrar una imagen conveniente ya que eran examinadas por parte de las familias o "señoritas" que las emplearían; la intensidad con que eran escrutadas estaba en proporción directa al poder adquisitivo y la clase social de las familias contratantes (como se apuntó en el epígrafe anterior):

Según contaba mi madre, toas las amas de dar teta se ponían con sus uniformes blancos, sus delantales [...] familias ricas pa que agarraran el camino y vieran la clase de persona... tenías que ir con una educación y una cosa... hablando de... lo que iban a hacer, lo que no iban a hacer [...] No te vayas a crees que se ponía cualquiera... [tenían que] ianalizar la teta! Mi madre dice que era... un sábado, fin de semana. No te vayas a creer que metían una cualquiera. Tenían que entrarle por los ojos.

Las amas de teta debían registrarse en una oficina situada "bajando las escaleras de la catedral", donde se formalizarían los contratos. Para el caso de Olema, la suerte tocó a su puerta (así como a la de la familia y el niño 
que se benefició de su leche, ya que veremos cómo la simbiosis de ayuda es potente) uno de esos días cuando, casi in situ, amamantó a un bebé necesitado en un coche (contado por Ani su hija):

En tiempos de la guerra, te lo via contá... mi padre enfermó del corazón y mi madre... como tenía tanta teta, que tenía unos cañones de teta que le salía que pa qué, pues se colocó de ama... de teta [énfasis] en la cuesta Gomérez con unos señoricos... se llamaba él Pablo y la señora se llamaba doña María, sabes... pues tenía un niño que estaba enfermico, que estaba encanijao [...].

Dice mi madre que llegó un día una señora y que le dijo llorando que se le estaba muriendo el crío y era de hambre, que le daba biberón... le daba biberón y no quería, le daba esto y tampoco lo quería, y mi madre dice "dónde está el niño"; se metió la madre en el coche y se colgó al niño en la teta, y le dio la teta al niño... con unas ganas [mucho énfasis], estaba el niño esmayaíiiico, dice "me hasía así, en la teta, me estrujaba, pa que saliera más, y yo le ponía así la teta... así que no podía, que me faltaba a mí la respiración" [...] se la llevó [la señorita], esta fue la de la calle Recogidas.

Se ha de precisar que estas "señoras" a las que hace referencia Ani, que en diversos momentos de su vida las contrataron (a ella y a su madre, siquiera informalmente) como nodrizas, eran, por lo general, según su propio testimonio, personas de una clase social bastante elevada y, por lo tanto, un poder adquisitivo notoriamente superior al de la propia Ani o su familia. El mismo hecho de que se refiera a ellas como "señoras", término que nunca usa para referirse a vecinas o comadres suyas, resulta indicativo de la distancia social percibida; otro indicio muy evidente del estatus lo aporta simplemente el dato de los lugares donde refiere que habitaban estas señoras y sus familias: por lo general, siempre se trata de calles céntricas de la ciudad de Granada, por ejemplo. Por otro lado, y aunque no sea el principal objetivo de este artículo el análisis del imaginario o ideario de maternidad que se construía basado en tener o no una nodriza, resulta de particular interés considerar que, cuando estas "señoras" se lo podían permitir, por estatus y economía, solían preferir contratar los servicios de un ama, frente a un amamantamiento personal, por así decir. (Remito para profundizar en estas cuestiones a las obras citadas en el marco teórico que sí abordan más directamente estas cuestiones.)

Regresando a Ani, ella por su parte entró en contacto con la familia donde ejerció más tiempo el oficio en la guardería social La Gota de Leche, en el Realejo. ${ }^{26}$ En este enclave, Ani acudía con su propia hija para amamantar, a cambio de ropa usada y poco más, a criaturas de otras familias 
cuyas madres no daban pecho. Fue en esa guardería donde Ani narra cómo un médico analizó su leche y le comunicó que era de alta calidad ${ }^{27}$ lo que ella llama "mollá":

El médico me analizó la teta y me dijo que la tenía "mollá" [...] pues la teta mejó... mu buena, mu buena, mu buena, y allí mismo en la Gota Leche, pues me vine a trabajar y yo pues daba teta, venían las señoritas, "mira Ani... a ver si se quiere venir a mi casa a que me críe a mi niño con la teta". Yo no daba abasto. A mí me lo miraron cuando yo estuve en la guardería, con un cristal... te ordeñas y se ve empañao y amarilla.

Entre las diversas peticiones de que Ani se convirtiera en nodriza exclusiva de alguna familia - se monopolizara por así decir - se destaca la de una señora (doña Mariana, esposa de don Miguel) que ella menciona como especialmente bondadosa ("que por cierto era mui buena") y que, por tener "mala teta" (gatuna) buscó sus servicios:

Aluego me salió una señorita que tenía... me metí a trabajar y tenía un niño que lo estaba [criando] ella, ella tenía teta pero la teta que tenía no le... era gatuna [...], pos que no vale, es agua... no le alimenta, y le decía la teta gatuna...

Las categorías sobre la leche, ampliamente documentadas por la historiografía de la lactancia, son reproducidas efectivamente por nuestra interlocutora sin asomo de duda. Afirma que el oficio de ama de teta se practicaba porque algunas señoritas no daban el pecho, lo que podía deberse principalmente a dos razones: impotencia percibida - no tener leche y/o no tenerla buena ${ }^{28}$ - o estética - no desear que el pecho "se estropee" con la lactancia:

(Se empleaban las amas de teta) porque no tenían buena teta y ... la que quería dar teta no daba porque decían que se le estropeaban los pechos... Decían "ay Ani, es que paso muncho, que se cuelga... que me salen hasta grietas... los caños tapaos... de la teta...".

En cuanto a la forma de organización doméstica del oficio, Ani cuenta que acudía al domicilio del niño que amamantó durante más tiempo por la mañana, temprano (a menudo llevando consigo a su hija más pequeña: "que yo llevaba muchas veces a mi niña grande, me la llevaba conmigo, y allí jugaba con el niño que yo le estaba dando teta, a la grande me la llevaba yo"), pasaba el día entero allí y se iba por la noche, a escondidas de la criatura que cuidaba para que no llorara (evidentemente, el vínculo emocional entre ellos era crucial), y siempre habiendo dejado algún biberón 
preparado para las horas de la noche; para ello, se extraía (ordeñaba) ella misma la leche durante el día, además de amamantar y cuidar al pequeño en general (con otras labores como darle otras comidas, bañarlo o pasearlo); así, es importante enfatizar que no dormía en casa de sus empleadores, de modo que no renunciaba completamente a cuidar de su propia familia e incluso seguir lactando a su hija pequeña. ${ }^{29}$

Yo estaba por la mañana, hasta las 8 o las 9 y ya me iba yo $p^{\prime}$ arriba, eso con la Julia, cuando estaba criando a la Julia... sí, me iba a las 9 de la noche, y aluego ya pues ordeñaba la teta, dejaba un biberón, lo metían en la nevera y lo... se lo daba la señorita, y ya al otro día. Y al otro día a las 8 de la mañana tenía que estar allí. Bañaba al niño, lo preparaba y me iba con él... en un carro de esos antiguos, porque ahora hay mucha modernura [...].

Muchas veces por la tarde me tenía que ir a escondías... lo dejaba dormío, acostao en la cuna... trincaba el camino, le decía: "ya hasta mañana no te doy teta" [...]. Yo me la sacaba y le dejaba biberón, se la daba, ella la metía en la nevera... pilla el camino, te sacas la teta, la metes en el biberón y se lo das.

Era también frecuente que se lo llevara con ella a pasar el día a su propia casa, a que jugara con sus hijos y ella misma pudiera a la vez ocuparse también de ellos. Destaca la relación tan estrecha que se establecía con la criatura lactante, como mencionábamos, que no admitía separarse de Ani y se encontraba más unida a ella que a cualquier otra persona, cuestión que ella comprende y explica con contundencia por la alta consideración que muestra de la propia práctica lactante, llegando a afirmar que "salvó la vida" de aquel niño:

Yo he cogío al niño muchas veces y me lo he llevao a la Haza Grande ${ }^{30}$ con mi niña, le decía a la señora "que me lo llevo" y el niño se venía conmigo, y no quería estar ni con la madre... iiLe salvé la vida!! Se ponía la señora: "iay, qué daría yo... mi vida daba... por lo que has hecho por mi hijo!".

Destaca también, así, el inmenso agradecimiento que la madre biológica muestra a lo que Ani hace por su hijo. En ocasiones daba el pecho al mismo tiempo, en tándem, al niño de la casa y a su propia hija; esta forma de tándem fue habitual tanto cuando ejercía el oficio como cuando amamantaba solo en esferas familiares o emocionales, incluso estando embarazada ("Estaba embaraza de ella y mi niño grande, me lo colgaba, con los calostros y to el embarazo él se lo mamó"), y cuando ello sucedía era frecuente que las criaturas amamantadas se tocaran, a veces no siempre pacíficamente ("la niña intentaba sacarle los ojos al pequeño", contaba entre risas). 
Por otro lado, Ani narra diversas técnicas que ella misma practicaba consigo para solucionar problemas frecuentes en los pechos lactantes, como el recién narrado de las obstrucciones mamarias que pudieran derivar en mastitis; así, para "desatascar" lo que Ani llama "caños" (y la ciencia "conductos galactóforos"), explica cómo se aplicaba un peine en el pecho o cómo colocaba al lactante para que succionara en el sentido inverso al habitual (esta última práctica muy recomendada por las asesoras de lactancia contemporáneas):

Que me abría el cañillo un peine, y me hacía así, me lo quitaba con un peine... o me colgaba a un niño al contrario, lo sentaba aquí [lo indica con gestos] y me lo colgaba en el pecho y hacía "oao..." [exclamación de gusto] y ellos mismos me lo destapaban. Y las grietas... hasta grietas, mis niños se mamaban hasta la sangre... eso era sufrir... no como ahora, que paren un niño y... de la frialdad del váter le salen almorranas. Uy es verdad. Ahora no se aguanta na...

En cuanto a la remuneración, Ani cuenta que tanto a su madre como a ella siempre les han pagado míseramente el oficio de ama de teta ("A mi madre le daban una peseta. Seis reales. Una miseria"), incluso cuando han estado empleadas en casas de señoritos un tiempo largo (en el caso de Olema, en calle Recogidas; en su caso, en calle San Miguel), siendo mayores las compensaciones en especie (comida, ropa usada para sus propia prole) y una cierta seguridad en forma de capital social (estar trabajando como persona de confianza en casa de unos señoritos), que el sueldo monetario en sí mismo. Existe, eso sí, el reconocimiento firme de que debería estar mucho mejor pagado: "Ya ves tú lo que ganaba... mal pagao. Sí, ganaba mu poquito. Las amas de teta... le tenían que pagar bien, y no lo pagaban".

Ani continuó practicando el oficio de ama de teta, pero nunca de forma tan continuada, incluyendo permanencia diurna, como en la casa del niño de la calle San Miguel, donde estuvo contratada hasta que este cumplió cinco años: "En otras casas ha dado un poco de teta, iba, daba teta y me salía... pero no tanto como con... esta señora (con ella estuvo)... cinco años. Ya le daban de comer...".

\section{- b) La teta para quien (se) ama: las propias criaturas y más allá}

Aunque la cuestión que nos ocupa de modo central aquí es la de la lactancia asalariada, destaca en la experiencia de Ani, ligada sin duda a su oficio de ama de teta, el amamantamiento que practicó durante muchos años no solamente con su propia prole o familia primaria por así decir, sino también con sobrinos e incluso nietos, lo que nos permite explorar y tentar el interesante concepto de teta transgeneracional. 
Ensayamos primero un sucinto cronograma de lactancia, o herstory de vida láctea, de nuestra principal interlocutora. Estimamos que nace en 1941 o 1942 (dice tener setenta y cuatro años en abril de 2016); a los once años empieza a trabajar como "doméstica" (chica) en una casa, a los catorce años contrae matrimonio y a los quince pare su primer hijo, pariendo a la última a los cuarenta y dos ("Yo mi Nines la tuve con cuarenta y dos años, la última con cuarenta y dos años la he tenío"). Ello da un margen de veintisiete años de embarazos, partos y lactancias, lo que naturalmente supone un rango más que suficiente para amamantar a los propios nietos.

En cuanto a su propia prole, Ani amamantó a todos hijos e hijas aproximadamente entre dos y tres años, casi siempre practicando tándem y continuando la lactancia durante el embarazo: "Le dao, le dao yo a tos mis niños hasta tres años. Mi Dioni se tragó los calostros de ésta embarazaá... estaba yo embarazá de esta y al otro colgao a la teta, le daba su teta [...] hasta dos y tres años...".

Varias de las hijas de Ani también han dado el pecho de forma prolongada, lo que ella siempre invariablemente reconoce como positivo frente a otros tipos de alimentación, aunque dando por hecho que solo "cuando la teta es buena", asumiendo que hay tetas "no buenas":

La Rut también ha dao mucha teta, esa ha criao a sus hijos a teta. Y mi Teresa... tres años de teta le ha dao a su niña... cuando es buena es buena [...] le salen unos caños de teta.... Se lo dije: 'Teresa... esa teta es buena'. Porque las tetas, siendo buenas, pues le da muchas defensas a los críos, no se les resfría... no se le ponen malos... yo los he criado a los míos acebonaos, yo les he dao na más que teta, yo no les he dao biberones. A mí me daba miedo darles de comer... me daba miedo eh... a ver si le via dar esto y le sienta malamente.

Sin embargo, acaso el aspecto más interesante que narra Ani, por infrecuente ya y extraño en nuestros días, es como decíamos, el hecho de haber amamantado a sus propios nietos; no tal vez como una lactancia cotidiana, diaria, como fuente principal o única de nutrición, sino como recurso en momentos puntuales en que las criaturas se quedaban con ella o lo necesitaban más por motivos diversos. Mientras ello sucedía, lógicamente, Ani estaba todavía amamantando a algún hijo propio, que debía compartir el pecho de su madre con sus sobrinos de igual edad, no siempre, como apuntábamos más arriba, con total aquiescencia:

Y a mis nietos también les he dao, claaaaro a mi nieta, mira a la otra, al Pepe. Y a mis sobrinos. Y a mis sobrinos. Claro, vino mi niño un día, se fue de fiesta, que vino de Salobreña, toma te lo via dejá... y estaba criando al Daniel [... ] y me colgué a mi nieto y mi niño le pegaba porque no quería... no quería que le diera. 


\section{- c) La teta para quien la necesita: el puro altruismo con el vecindario}

Ani se identifica plenamente con su madre, como hemos ido repasando, en dos hechos fundamentales, autodescritos como tener "mucha teta" y tenerla "buena". Ello se complementa como veremos con una categoría fundamental persistente en toda su narración, ligada a tener buena teta o no, incluso mencionándose etiquetas diferenciadas para las buenas (mollás) y malas tetas (gatunas), y el hecho de ello se certificaba con pruebas médicas o de laboratorio. Esa mencionada hiperproducción de una leche muy buena justifica o explica tanto la práctica del amamantamiento remunerado cuanto el amamantamiento largo tiempo no solo de los propios hijos sino de sobrinos, nietos o vecinos, por pura solidaridad:

Yo le decía a los gitanillos ${ }^{31}$ del Polígano, ya vivía yo en el Polígano [...] viene una chiquilla y me dice "ay Ani... y está llorando mi hermano, por qué no le das una gotica de teta...", pos yo pillaba el camino y me lo colgaba... iiy le daba su teta porque tenía muncha teta!! iiY buena!! Porque he dao muncha teta.

Así, las razones para amamantar a criaturas que no son de la propia familia se ligan con el puro altruismo, la solidaridad que genera la sensación de lástima; este hecho además es descrito con mucha firmeza, incluso orgullo y dignidad, con conciencia de haber hecho algo bueno, algo importante frente al descuido o la imposibilidad de presencia de otras madres:

Hasta a los gitanillos del Polígano les he dao yo teta, que me daba lástima, que estaban los chiquillos llorando, se iban las madres a trabajar... y pues me... tráelo $p^{\prime}$ acá que le via dar teta, y me lo colgaba... [con afirmación], me decían: "límpiate el pezón", digo: "qué me voy a limpiar yo ná, é un niño, qué asco le voy a tener yo...", y cuando venía la madre le decía a la niña grande "¿qué ha comío el niño?", "qué quieres que coma el niño, iipues teta de la Ani!!, que lo he llevado que le dé teta". Yo le daba su teta [con convicción].

Sin embargo, este altruismo tiene limitaciones, por ejemplo, cuando la propia madre biológica está presente, le llega a demandar teta para su criatura y Ani considera que es la madre la que debe darla:

Había una gitana en el Polígano que agarraba el camino y me decía: "por qué no le das teta a mi niño", y le decía: "por qué no le das tú, tú tienes los pechos esos que... los estoy viendo arreondos", y me decía: "aaaay hermanica, es que tengo grietas", y qué grietas que tenía y he tenío yo, los caños tapaos y tó, y me colgao a to er que he pillao me lo he colgao. 
Es obvio que se percibe un elemento de cuidado ético en dar o no la teta: si se puede dar, a pesar de las grietas, las molestias o los dolores, no se comprende que no se dé a los propios hijos. Ello no está reñido con una conciencia muy fuerte de que hay tetas "malas", que "no sirven", a pesar de la voluntad de la madre, y eso no tiene remedio (dejando a un lado la cuestión de que no se quiera dar por estética, "pa que no se estropearan los pechos", lo cual evidentemente se presenta como un privilegio de clase alta, de señoritas ricas).

\title{
A modo de reflexiones conclusivas: de la subalternidad lactante al empoderamiento
}

\author{
“[...] Te permito morder, lamer, sanar. \\ Tú bebes de los ríos de mis senos \\ el agua de las rocas frente al mar. [...]" \\ (Acosta 2017) \\ "Tus tetas son bonitas porque tienen leche." \\ (Lactante de tres años a su madre) \\ “- Abuela, dame teta. \\ - Pero mis tetas no tienen leche. \\ - No pasa nada. También me gustan sin leche." \\ (Lactante de tres años a su abuela)
}

El pecho, como el ser aristotélico, se dice de muchas maneras. Cuanto más nos acercamos a la lactancia humana, más vectores de comprensión, encrucijadas y matices hallamos en ella. Los estudios contemporáneos sobre lactivismo ${ }^{32}$ nos muestran una vía política experiencial del empoderamiento a través de la lactancia, frente a cierta situación de subalternidad que encontrábamos en algunos ejemplos sobre lactancia mercenaria (insistimos, no en todos). Esta historia y su reflexión se enmarcan, pues, en un debate más amplio sobre el concepto de subalternidad y la inversión simbólica incluso que la leche materna, a través de movimientos como el lactivismo, está experimentando.

Del mismo modo que la interpretación de la Naturaleza como concepto está siendo revisada desde el feminismo, así hoy el concepto de subalternidad no puede ser tampoco el mismo que hace treinta años, cuando, aun siendo 
igualmente contencioso (lo ha sido desde sus orígenes), estaban mucho más claros los dos extremos del poder y del margen. En palabras literales de Chatterjee (en Uday 2015:569): "Subaltern Studies was a product of its time; another time calls for other projects". ${ }^{33}$

En la doble historia recogida destacan los siguientes elementos fundamentales:

- El elemento del altruismo, o cómo se da el pecho no solo por dinero a personas que no son familia directa o indirecta.

- El elemento transgeneracional, o cómo se da el pecho a familiares de otras generaciones.

- El elemento o matiz de clase para los estudios históricos sobre nodrizas: las nodrizas, y los andamiajes de tabús y prescripciones morales que se les pudiera requerir o no en cada época, dependían de la clase social de los contratantes; dicho de otro modo, las amas de tetas eran como se las podían permitir sus empleadores, y por tanto el tipo de requerimientos morales propios de las clases más altas, como el no poder mantener relaciones sexuales adultas o tener que residir por la noche también en la casa, no entraban siquiera en consideración para nodrizas de extracción social pobre. En esa medida, la Gota de Leche era el remedio para madres con "tetas gatunas" pero con poco dinero o, como se decía, "la nodriza de los niños pobres".

Es muy posible que el altruismo esté ligado a la condición, precisamente, de clase subalterna en estas nodrizas; es decir, que la propia situación de subalternidad que padecían Ani y su familia acrecentaba su sensibilidad hacia el dolor ajeno y la movía a ayudar, en fin, a sus "vecinicos pobres y gitanos" de la mejor forma que sabía: dando nada menos que su leche. Como un regalo, en una pura relación de don. ${ }^{34}$ El cómo en situaciones de adversidad se extrema la capacidad de altruismo y empatía entre seres humanos (en lugar de, por ejemplo, enfatizarse su egoísmo para concentrar recursos) es descrito como un rasgo clave de nuestra condición animal, mamífera, de primates profundamente altriciales. El periodista Sebastian Junger (2016:93) recuerda en su lúcido ensayo Tribu: sobre vuelta a casa y pertenencia, que "Dos de los comportamientos que separaron a los primeros humanos fueron el compartir sistemáticamente los alimentos y la defensa altruista del grupo [...] y esos comportamientos les ayudaron a situarse en un camino evolutivo que produjo el mundo moderno".

Entre los muchos ejemplos que aporta su reflexión sobre gestos altruistas ofrecidos por personas en situaciones de franca desposesión, Junger no 
incluye ninguno sobre madres que dan su leche de forma altruista, pero el que hemos visto bien pudiera formar parte de aquel hermoso elenco. "Ese sentido de solidaridad está en el núcleo de lo que significa ser humano, e indudablemente ayudó a que llegásemos a este extraordinario momento de nuestra historia. Puede que también sea lo único que nos permita sobrevivir a este momento" (Junger, 2016:106), asevera Junger, en una impresión que ciertamente comparto. Por ello es importante recordar - volver a pasar por el corazón - historias como las de Ani y su madre, nodrizas clásicas que ya están muriendo, cuyo testimonio en breve dejaremos de poder escuchar de primera mano, y que muestran cómo personas empobrecidas, excluidas, han sobrevivido gracias a la leche de sus pechos, pero también han dado vida con ellos, en un movimiento de ida y vuelta difícilmente discernible.

Las madres han dado pecho (y no dado) por muchas razones. El placer y el altruismo, su concomitancia precisamente, son algunas de las más poderosas, y las hallamos presentes incluso en personas que han vendido el producto, que han intercambiado el uso lácteo por bienes monetarios para mantener a su propia familia biológica. Nuevamente hallamos que la lactancia humana desborda con creces cualquier otro fenómeno comparable: igual que la sexualidad entre personas adultas, y su comercio en el caso de la prostitución, involucra debates y elementos intransferibles a los propios de otras transacciones, ventas o empleos, así la historia, y el presente, del amamantamiento de las nodrizas se muestra complejo y rico, porque tiene que ver con cuerpos, carnes, afectos, placeres... mujeres que se hallan en su puerperio, a menudo, con pechos y tripas abultados y fluidos, y criaturas sin voz pública o política, pero que aman y tocan, y gozan y dan placer de un modo igualmente único e intransferible.

Recebido em: 30 de outubro de 2018

Aprovado em: 03 de dezembro de 2018

\section{Agradecimientos}

Gracias al ama de teta que se narró a sí misma en esta historia y la de su madre. Gracias a mi amiga P., por hablarme de ella y conducirme hasta ella, y acompañarme mientras se narraba. Gracias a mi pequeña tribu lactante, por enseñarme, primero, que estas historias contaban.

Ester Massó Guijarro

Doctora por la Universidad de Granada (2009), licenciada en Filosofía y en Antropología Social y Cultural (2003) por la misma Universidad, y Máster en Cooperación Internacional por las Universidades de Granada y de Santiago 
de Compostela (2005). Ha sido investigadora contratada predoctoral (FPU) en la Universidad de Granada y posdoctoral (JAE DOC) en el CSIC (Madrid). Ha impartido docencia en licenciatura, posgrado y formación continua universitaria. En la actualidad es profesora contratada doctora del Departamento de Antropología Social de la UGR, acreditada por ANECA a profesora titular desde 2015 y con dos sexenios de investigación consecutivos reconocidos por ANECA. Cv extenso: http://antropologia.ugr.es/pages/personal/ficheros/_doc/ ester/\%21ester@ugr.es 


\section{Referencias bibliográficas}

ACOSTA, Delfina. 2017. "La nodriza". Disponível em: http://www.lospoetas.com/d/delfina1.htm.

AKRE, James; GRIBBLE, Karleen \& MINCHIN, Maureen. 2011. “Milk sharing: from private practice to public pursuit". International Breastfeeding Journal, 6 (1):8.

BELZA, Julio. 1997. Las calles de Granada. Granada: Comares.

BERGÈS, Sandrine \& COFFEE, Alan N. S. J. 2016. The Social and political philosophy of Mary Wollstonecraft. Oxford: Oxford Scholarship.

BOURDIEU, Pierre. 1998. Razones prácticas. Barcelona: Anagrama.

CARDWELL, Richard. 2003. "Máscaras poéticas y suplementos psicológicos en dos poemas del Romancero Gitano". In: T. J. Dadson \& D. Flitter (eds.), La poesía española del siglo XX y la tradición literaria. Birmingham: The University of Birmingham Press. pp. 16-32.

CARSTEN, Janet. 1997. The Heat of the Hearth The Process of Kinship in a Malay Fishing Community. Oxford: Clarendon Press.

CAVARERO, Adriana. 2007. Tu che mi guardi, tu che mi racconti. Filosofia della narrazione. Milán: Feltrinelli Editore-Collana Elementi.

CERVANTES SAAVEDRA, Miguel de. 1994. Don Quijote de la Mancha. Barcelona: RBA.

FRAILE GIL, José Manuel. 2000. Amas de cría. Valladolid: Fundación Joaquín Díaz.

HAN, Byung-Chul. 2010. La sociedad del cansancio. Barcelona: Herder.

HASSAN, Narin. 2016. "Feeding Empire: Wet Nursing and Colonial Domesticity in India". NineteenthCentury Contexts. An Interdisciplin- ary Journal "Natural and Unnatural Histories", 5-38:353-363.

HERNÁIZ Gómez, Luis \& SAIZ PUENTE, María Soledad. 2010. La vida láctea: historia del amamantamiento. Madrid: Foren21 Formación.

HEWLETT, Barry S. \& WINN, Steve. 2014. "Allomaternal nursing in humans". Current Anthropology, 55 (2) :200-229.

JUNGER, Sebastian. 2016. Tribu. Sobre pertenencia y vuelta a casa. Madrid: Capitán Swing.

MARTÍNEZ SABATER, Antonio. 2014. Las nodrizas y su papel en el desarrollo de la sociedad española. Una visión transdisciplinar. Las nodrizas en la prensa española del siglo XIX y principios del siglo XX. Tesis doctoral, Universidad de Alicante.

MASSÓ GUIJARRO, Ester. 2015. "Lactivismo contemporáneo en España: ¿nueva marea sociopolítica?". Journal of Spanish Cultural Studies. 16 (1):1-21.

MUÑOZ PRADAS, Francisco. 2016. "La implantación de las gotas de leche en España 1902-1935: un estudio a partir de la prensa histórica". Asclepio. Revista de Historia de la Medicina y de la Ciencia, 68 (1):0210-4466.

OZTURK CAN, Hafiz; YESIL, Yesim; EKSIOGLU, Aysun \& CEBER TURFAN, Esin. 2014. “Women's views on wet nursing and milk siblinghood: an example from Turkey". Breastfeeding Medicine, 9-10:559-561.

PINK, Sarah. 2010. "The future of sensory anthropology/the anthropology of the senses". Social Anthropology, 18-3: 331-340. 
POTTS, Malcolm M. \& SHORT, Roger. 2001. Historia de la sexualidad. Madrid: Cambridge University Press.

PULEO, Alicia H. 2009. "Naturaleza y libertad en el pensamiento de Simone de Beauvoir". Investigaciones Feministas, 0:107-120.

REBOREDA MORILLO, Susana. 2016. "La maternidad: desde la infancia a la adolescencia en la antigua Grecia". In: A. Hervás Delgado \& M. Picazo Gurina (eds.), Los trabajos de las mujeres en el mundo antiguo: cuidado y mantenimiento de la vida Huc et Nunc. Tarragona: Instituto Catalán de Arqueología Clásica: 119-128.

REYES-FOSTER, Beatriz M. et al. 2015. "Milk sharing in practice: a descriptive analysis of peer breastmilk sharing". Breastfeeding Medicine, 10 (5):1-7.

RODRÍGUEZ GARCÍA, Rita. 2017. "Nodrizas y amas de cría. Más allá de la lactancia mercenaria". In: Esther Massó Guijarro, Mamar: mythos y lógos sobre lactancia humana. Dilemata. Revista Internacional de Éticas Aplicadas, 25: 37-54.

SANTOS GOMES, Cristiane et al. 2015. "Lactancia cruzada, de la negligencia a las virtudes morales: estudio descriptivo". Online Brazilian Journal of Nursing. 14 (3) :263-72.

SARASÚA, Carmen. 1994. Criados, nodrizas y amos. El servicio doméstico en la formación del mercado de trabajo madrileño, 1758-1868. Madrid: Siglo XXI.

SHAW, Rhonda. 2003. "Theorizing breastfeeding: body ethics, maternal generosity and the gift relation". Body \& Society. 9 (2):55-73.

SILES GONZÁlEZ, José. 1996. "La industria de las nodrizas en Alican- te, 1868-1936". In: S. Castillo (ed.), El trabajo a través de la historia. Madrid: UGT - Centro de Estudios Históricos. Asociación de Historia Social. pp. 367-372.

SOLER, Elena. 2011. Lactancia y parentesco. Una mirada antropológica. Barcelona: Anthropos.

STEVENS, Emily E. et al. 2009. "A history of infant feeding". The Journal of Perinatal Education, 18 (2) :32-39.

THORLEY, Virginia. 2008. "Sharing breastmilk: wet nursing, crossfeeding, and milk donations". Breastfeeding Review, 16 (1):25-29. . 2009. "Mothers' experiences of sharing breastfeeding or breastmilk: co-feeding in Australia 19782008". Breastfeed Review. 17:9-18. . 2015. "A mother, yet not 'mother': the occupation of wet-nursing". Journal of Family Studies, Issue 3: Motherhood, Feminisms and the Future, 21.

TOLEDO, Víctor M. \& BARRERA-BASSOLS, Narciso. 2008. La Memoria Biocultural. La importancia ecológica de las sabidurías tradicionales. Barcelona: Icaria.

UDAY, Chandra. 2015. "Rethinking Subaltern Resistance". Journal of Contemporary Asia, 45 (4):563-573.

VERA LUGO, Juan Pablo \& JARAMILLO MARÍN, Jefferson. 2007. "Teoría social, métodos cualitativos y etnografía: el problema de la representación y reflexividad en las ciencias sociales". Universitas Humanística. 64:237-255.

WARING, Marilyn. 1994. Si las mujeres contaran. Una nueva Economía Feminista. Madrid: Vindicación Feminista.

WEST, Emily \& KNIGHT, R. J. 2017. "Mothers' Milk: slavery, wetnursing, and Black and White 
women in the Antebellum South. Journal of Southern History, 83 (1):37-68.

WRIGHT, Anne L. et al. 1993. "Cultural interpretations and intracultural variability in Navajo beliefs about breastfeeding". American Ethnologist, 20 (4):781-796.
YALOM, Marilyn. 1997. Historia del pecho. Barcelona: Tusquets.

YOUNG, Iris Marion. 2005. Breasted experience. Throwing like a girl and other essays in feminist. New York: Oxford University Press. 


\section{Notas}

1 Cf. el interesante término en Toledo y Barrera-Basols (2008).

2 La OMS, y tantos otros organismos ya sean científicos, sociales, etc., suelen transmitir este mensaje en un sentido de "lo natural" como "fisiológico", aunque la cuestión conlleva un irredento debate desde los diversos feminismos.

3 "Cuanto más abstracta sea la verdad que quieres enseñar, tanto más tienes que atraer hacia ella incluso a los sentidos [...] De los sentidos es de donde procede toda credibilidad, toda buena conciencia, toda evidencia de la verdad (Nietzsche en Massó Guijarro 2015:252).

4 Cf. la "breasted experience", de Young (2005).

5 La misma Puleo precisa que "La visión beauvoireana del ser humano corresponde, punto por punto, con el dualismo antropocéntrico extremo y con la total adhesión entusiasta a la fe en el progreso tecnológico. El perfeccionamiento humano es visto como un proceso de creciente dominio sobre la Naturaleza que conduce triunfalmente al poderío nuclear" (:117).

6 La metáfora ha sido usada en muchas ocasiones por su fuerza simbólica y expresiva; por ejemplo, el título del riguroso recorrido histórico de Hernáiz Gómez y Saiz Puente es, precisamente, "La vida láctea" (cf. Massó Guijarro).

7 http://www.llli.org/llleaderweb/lv/lvjulaug95p53.html

8 Cf. Thorley $(2008,2009)$ y Shaw $(2003: 238)$. Para "cross-milk" hemos encontrado también el uso de "peer-breastmilk" (Reyes-Foster et al. 2015).

9 http://dle.rae.es/?id=2ND9BMI

$10 \mathrm{http} / / /$ dictionary.cambridge.org/es/diccionario/ingles/wet-nurse

11 Ver el uso del término en Santos Gomes et al. (2015). Por otro lado, proliferan los testimonios directos al respecto de las madres en sus propios blogs; véase este a modo de ejemplo significativo, ya que la "madre de leche" - autodenominada así recomienda la experiencia intensamente: http://www.280dias.com/lactancia-cruzada/

12 Cf. la excelente revisión de Rodríguez García (2017); Stevens et al. (2009:32ss) y Hernáiz y Sáiz Puente (2010) para una crónica general de la historia de las nodrizas; cf. Yalom (1997). Desde una perspectiva etnológica, Wright et al. (1993) informa sobre la lactancia entre los navajo. Yéndonos mucho más atrás, podemos bucear en ciertas hipótesis sobre la lactancia a través de la compilación de Romero y Alarcón García (2015), que se aproximan al estudio arqueológico de la lactancia en la antigüedad.

13 Ver, por ejemplo, el estudio sobre la llamada lactancia de limosna en Valencia durante el siglo XVIII, estudiada por Bolufer (en Rodríguez García 2017).

14 Cf. Reboreda Morillo (2016). 
15 Fraile Gil (2000) realiza un recorrido histórico-gráfico, bien que divulgativo, igualmente de gran interés sobre la cuestión.

16 En esta línea, Hassan (2016) presenta un fascinante trabajo sobre cómo las representaciones de las nodrizas en la India decimonónica ayudan a comprender las relaciones coloniales.

17 Hoy en día es frecuente el comercio de leche humana entre particulares a través de Internet en Estados Unidos, Canadá y Reino Unido (ver páginas especializadas como Eats on Feets, Human Millk 4 Human Babies y Only the Breast). Akre et al. (2011) analizan cómo el compartir leche ha evolucionado de una práctica privada a un asunto (y negocio) público.

18 Cf., por ejemplo, la reflexión de Bergès y Coffee (2016) sobre las nodrizas y la participación política en el contexto inglés decimonónico.

19 Véase por ejemplo el estudio de Muñoz Pradas (2016).

20 Todos los nombres propios, ciertos topónimos, etc., salvo el mismo de Plaza de las Pasiegas u otros irrelevantes para un posible reconocimiento identitario, han sido alterados para respetar el anonimato.

21 Para conocer algunas generalidades sobre esta localidad, capital de provincia, véase, por ejemplo, https://es.wikipedia.org/wiki/Granada

22 Ambas son de profesión católica y prácticamente analfabetas, sin haber podido completar nunca una escolarización mínima. Repárese en que la Guerra Civil española termina en 1939, apenas dos o tres años antes del nacimiento de Ani; es decir, ella llega al mundo en plena posguerra, un período marcado en España por la inmensa pobreza, el aislamiento internacional y, en suma, una dictadura de corte fascista que durará cuarenta años.

23 En la medida de lo posible se respetan todas las formas dialectales de habla, siempre que no comprometa la comprensión de la frase.

24 Tanto el "Polígano" (Polígono de Cartuja) como la Virgencita hacen referencia a barriadas pobres y marginales de la ciudad de Granada, zonas suburbiales aún ahora asociada con viviendas sociales, venta de droga y prostitución, así como problemas diversos vinculados a la exclusión social.

25 Belza (1997:187), en su obra sobre las calles de Granada, recoge en un breve párrafo la historia del apelativo popular "Plaza de las Pasiegas". Las amas de teta entrevistadas no mencionan a las pasiegas en ningún momento.

26 Antiguo barrio judío del centro de Granada.

27 Otro prejuicio rebasado: no hay leches mejores que otras, si bien, como se señaló en el apartado teórico, este prejuicio ha pervivido durante siglos, y hasta hoy.

28 La hipogalactia real, como trastorno fisiológico, es sumamente infrecuente, como han documentado las ciencias de la salud contemporáneas, aunque no es asunto de este trabajo realizar estas confrontaciones. 
29 Todo ello altamente frecuente en las nodrizas de clases más altas (cf. Soler 2011).

30 Otro barrio periférico y suburbial, históricamente pobre, de Granada.

31 La historia del pueblo gitano o romá en España supone una crónica secular de racismo y exclusión. En el discurso de Ani, y aunque no pueda profundizar en ello ahora ya que se aleja mucho del objetivo de este trabajo, se reproduce el estereotipo separador de "gitanos" y "no gitanos", aunque convivieran en idénticos lugares y situaciones. Ello, por otro lado, aporta todavía más fuerza y sentido a que ella diera su leche, por motivos altruistas, a niños gitanos.

32 Cf. Massó Guijarro (2015).

33 Para una revisión reciente de las ambigüedades y ambivalencias inherentes a la resistencia subalterna de Spivak, frente a las formaciones sociohegemónicas, y una reconceptualización de ello como la negociación (más que la negación) del poder social, ver Uday (2015:563).

34 Cf. la interesante reflexión de Shaw (2003) sobre la ética del amamantamiento y la relación de "regalo" o "don" que supone para sus casos estudiados. 


\section{"LE SALVÉ LA VIDA": EL PECHO VIVIDO, LA LECHE NARRADA. HISTORIA(S) DE AMA DE TETA, SUR DE ESPAÑA, SIGLO XX}

\section{Resumen}

El presente artículo aborda la historia reciente de las nodrizas (amas de cría o amas de teta) en el sur español a través de la técnica de historias de vida, en concreto la reconstrucción biográfica de la experiencia personal de dos nodrizas, madre e hija (aún viva, que ha ejercido de narradora). La relevancia de estos testimonios radica en que aportan información de gran calidad sobre la experiencia del amamantamiento de estas personas como nodrizas, que hemos dado en llamar "subalternas", en torno a una parte de la historia social y de las mujeres que resulta bastante invisible y silenciada en estudios hasta la fecha.

El artículo aborda primero un marco teórico sobre la allomaternal nursing para, después, presentar pormenorizadamente el estudio de caso. Los principales hallazgos etnográficos permiten desarrollar un análisis sobre cómo las protagonistas de estas lactancias campan de la "subalternidad lactante" al empoderamiento a través del valor del altruismo. La filosofía de la narración y el enfoque de la recogida de herstories de vida láctea serán cruciales para desarrollar el marco epistemológico y metodológico de este trabajo.

Palabras clave: historias de vida (láctea), amamantamiento, subalternidad, altruismo, empoderamiento, lactancia materna.

\section{"EU SALVEI A SUA VIDA": 0 PEITO VIVIDO, O LEITE NARRADO. HISTÓRIA (S) DE AMA DE TETA, SUL DE ESPANHA, SÉCULO $X X$}

\section{Resumo}

A história recente de amas de leite no sul da Espanha é apresentada através da técnica de histórias de vida, especificamente a reconstrução biográfica da experiência pessoal de duas amas, mãe e filha. A relevância desses depoimentos é que eles fornecem informações de alta qualidade sobre a experiência de amamentar essas pessoas como amas, chamamos "subalternas", em torno de uma parte da história social de mulheres que são bastante invisíveis e silenciada em estudos até o momento. O artigo primeiro aborda um enquadramento teórico sobre a allomaternal nursing para, então, apresentar detalhadamente o estudo de caso. Os principais achados etnográficos permitem desenvolver uma análise de como os protagonistas dessas lactações variam de "subalternidade de sucção" a empoderamento através do valor do altruísmo. A filosofia da narrativa e a abordagem de colecionar histórias de vida leiteira serão cruciais para desenvolver o quadro epistemológico e metodológico.

Palavras-chave: histórias de vida (laticínia), amamentação, subalternidade, altruísmo, empoderamento, lactância materna. 


\title{
"I SAVED HIS LIFE": THE LIVED \\ BREAST, THE NARRATED MILK. HISTORY AND HERSTORIES OF WET \\ NURSINGS, SOUTHERN SPAIN, 20TH CENTURY
}

\begin{abstract}
The recent history of wet nurses in Southern Spain is presented in this article through life stories, specifically the biographical reconstruction of the personal experience of two wet nurses, a mother and her daughter. These testimonies are relevant in that they provide high quality information on the breastfeeding experience of these subaltern nurses, as a part of a feminine history that has thus far remained muted in academic studies.

The article first addresses a theoretical framework on allomaternal nursing in order to then present the case study in detail. The main ethnographic findings allow us to develop an analysis of how the protagonists of these lactations shift from a "suckling subalternity" to empowerment through the value of altruism. The philosophy of the narrative and the approach of collecting herstories of dairy life will be crucial to develop the epistemological and methodological framework.

Keywords: life (dairy) stories, breastfeeding, subalternity, altruism, empowerment, human lactation.
\end{abstract}

